\title{
Nature for non-English speakers
}

SIR - My advice to the Japanese journalist whose translation machine failed to explain the meaning of "Prides and prejudice" (Nature 359, 475; 1992), is to acquire the Oxford English Dictionary. The second edition, available in 20 volumes or on disk, gives as one of the definitions of "pride" "a group of lions forming a social unit". In addition, it lists the phrase "pride and prejudice", which is illustrated by 10 examples, the first dating from 1619, while the last gives the title of Jane Austen's novel, published in 1813. This makes an understanding of the phrase independent of one's knowledge of English literature.

Admittedly, anyone without access to sufficient funds in hard currency may have to make do with the two volumes of the Shorter Oxford English Dictionary. These do not include "pride and prejudice", but nevertheless give the necessary definitions of "pride", "Herculean", "Augean" and "Noah's Ark", although the entry on "Damascus" fails to inform on Paul's conversion.

All in all, baby language is hardly called for in an effort to make science intelligible. On the other hand, the use of slang would be totally out of place. Readers of Nature naturally need to understand its contents, but also use its style as a model in writing or giving talks in English. It is far less difficult to understand the meaning of a word in a foreign language than to acquire a feeling for its exact status. Many years ago, a German-speaking colleague, about to give a talk at a genetics meeting, asked me to look at the English of his manuscript. The only change needed was to substitute "hybrid" every time the word "bastard" occurred.

Equally, portmanteau adjectives, such as "DNA-dependent cytosol-controlled", owe nothing to the idiosyncrasies of English syntax and everything to scientists cutting corners in their use of language. If editors were to develop a healthy immune response in the face of these linguistic invaders, this would be a small step leading to a better understanding of science.

\section{Ursula Mittwoch}

Queen Mary \& Westfield College,

Mile End Road, London E1 4NS, UK

SIR - Although I am neither a native speaker of English, nor among the happy few who understood the pun about "Prides and prejudice" at first glance (actually I learned the word for a group of lions from this cover), I hope you will maintain this kind of allusive writing. Critics should take into account that a headline of a News and Views item, Commentary and so on cannot actually provide a short cut to spare one the trouble of reading the page by conveying the same information in a nutshell. At best it can attract the reader's attention so that s/he will read the article. Thus, a little bit of mystery in the headline need not be an impediment to understanding the body of the text.

Referring to your question of how to make an international journal more accessible to a polyglot audience, I plead for an educational approach. Instead of lowering the standard until the text becomes comprehensible to people without any knowledge of English (and unbearable for the rest of us), you should provide motivation for all scientists to reach a reasonable standard of English, including the cultural connotations of the language. One can certainly assume that the readers of Nature have intelligence and curiosity. Hence, a pun that they do not understand should be a challenge to think about the language. By keeping the 'literary' quality of its front pages, Nature will supply its readership with a valuable means to improve their English (for instance, if ever I meet a multitude of lions, I will always remember to address them as a pride and will never risk insulting them by confusing them with a pack of wolves, a flock of sheep or a gaggle of geese), whereas a process of receding to the smallest common denominator will accelerate the decline of scientific English towards a babytalk enriched by numbers and acronyms.

\section{Michael Gross}

\section{Institut für Biophysik}

and Physikalische Biochemie,

Universität Regensburg,

D-8400 Regensburg, Germany

\section{Hunterian Institute}

SIR - I read with great sadness lan Mundell's article (Nature 358, 704; 1992) concerning the closure and removal of several research departments at the Hunterian Institute based at the Royal College of Surgeons of England, which effectively closes the Hunterian Institute one year before the 200th anniversary in 1993 of John Hunter's death. This is in direct conflict with the principles of John Hunter who stressed that true learning was possible only against a background of research. A well-known quotation of Hunter, directed to his friend Edward Jenner, was, "Why think? Why not do the experiment?" Sadly, that is not going to be possible now for many people at the Hunterian Institute.

Mundell said that although staff at the institute are unhappy about the changes, they are reluctant to speak publicly. As a former $\mathrm{PhD}$ student and subsequently a research fellow at the Hunterian Institute, I feel it is the duty of all scientific staff to speak out strongly. For someone such as myself, just embarking on an independent scientific career, the loss of the Hunterian Institute is representative of a rapid demise in science in Great Britain and acts as another example to dissuade young graduates from entering science as a career (see Nature 355, 292; 1992). I left the Hunterian Institute earlier this year just before the news broke of its imminent closure. Like many other young scientists, including the final four PhD students who were trained in the department of biochemistry and cell biology, I am now working abroad. To some extent this is a normal career stage for postdoctoral graduates in order to gain a breadth of experience. But it is of great concern that there may be very few scientific jobs for which to return to Britain.

A factor that has compounded the closure of the institute is the lack of discussion between the staff, past council members and benefactors before the decision was made. During the final months of the institute, very little explanation was offered to members of staff as to why the institute was closing or what was to happen to their jobs. This lack of communication has resulted in some members of staff facing unemployment after many years of loyal and devoted service to the institute and college. The Royal College of Surgeons is a registered charity and relies upon public and industrial fund-raising for many of its activities; the appeal of the college to potential donors without many of its excellent research departments will be severely weakened. It is sad to think that a college of such excellence and once a great debating house in which the merits of Geoffroy's, Lamarck's and Cuvier's doctrines were discussed in such a radical and open way, no longer feels it necessary to continue that tradition. In the context of the National Health 'reforms' and publication of the Tomlinson report on the future of the London teaching hospitals, I hope a lesson will be learnt from this unhappy event; perhaps politicians and administrators of other institutes and medical schools will appreciate the excellent work their scientific colleagues are doing and attempt to help them in their endeavours, rather than closing them down. I feel that the Royal College of Surgeons, by closing down or moving most of the Hunterian Institute to make way for more office space, has done itself and British science a great disservice.

\section{Paul Eggleton}

Boston University School of Medicine, 80 East Concord Street, Boston,

Massachusetts 02118-2394, USA 